Keywords: Serotonin Syndrome; Fluvoxamine; Cytochrome P450.

\title{
Combination of fluvoxamine and analgesics can cause serotonin syndrome
}

\author{
Sanja Kovacic* \\ Silvio Vukovic* \\ Sandra Kocijan-Lovko** \\ Maida Seferovic* \\ * Department of Neurology, General \\ Hospital Zabok, Zabok \\ ** Department of Psychiatry, General \\ Hospital Zabok, Zabok
}

CROATIA

\begin{abstract}
Serotonin syndrome is a potentially severe acute adverse reaction to a serotonin agonist. It is characterized by cognitive and behavioral changes, autonomic dysfunction and neuromuscular abnormalities. The growing use of SSRIs is related to the frequency of the syndrome. The aim of our presentation was to describe a unique case of severe hyperserotoninergic state caused by a single dose of fluvoxamine and an analgesic drug. Physicians who prescribe SSRIs should be aware that the patient is not a medical specialist and needs detailed information on any new drug he has been prescribed.
\end{abstract}

Received 24 November 2007

Revised 10 November 2008

Accepted 18 November 2008

\section{Introduction}

Serotonin syndrome (SS) can be described as a potentially serious drug-related condition characterized by a number of mental, autonomic and neuromuscular changes ${ }^{1,2}$. It is usually associated with high doses of serotonergic drugs, when combinations of serotonergic agents are used together, or when antidepressants are changed without an adequate washout period between drugs. Selective serotonin reuptake inhibitors (SSRIs) are commonly prescribed psychotherapeutic agents. They have a high toxic-to-therapeutic ratio, and fatalities are uncommon with pure SSRI overdoses. More commonly an adverse drug reaction to SSRIs may be seen among older patients, who are particularly vulnerable to the serotonin syndrome due to multiple co-morbidity and polypharmacy ${ }^{3}$. 
We report a case of a young patient with serotonin syndrome induced by a combination of fluvoxamine (FLV) and an analgesic drug containing a fixed combination of paracetamol, propyphenazone and caffeine.

\section{Case report}

A 28-year-old depressed woman with tension headache was admitted to hospital for confusion, insomnia and nausea, vomiting, diarrhea and sweating. She complained of leg paresthesias. She had taken a $100 \mathrm{mg}$ tablet of fluvoxamine (FLV) for the first time in addition to an analgesic drug containing a fixed combination of paracetamol $(250 \mathrm{mg})$, propyphenazone $(150 \mathrm{mg})$ and caffeine $(50$ $\mathrm{mg}$ ) commercially available in drugstores as an over-the-counter medication. However, her doctor had recommended an initial dose of $50 \mathrm{mg}$ FLV at bedtime. The patient had never been treated by antidepressants before. The neurological examination revealed proximal muscle weakness, tremor, hypotonia, and myoclonal seizures, but there were no focal neurological findings. The patient's blood pressure was 115/90 mm Hg, her heart rate 130 beats/min, her respiratory rate 36 breaths/min and body temperature $37^{\circ} \mathrm{C}$. The ECG indicated sinus tachycardia. Her leukocyte count was $12 \times 10^{9} / \mathrm{L}$. Blood gas analysis showed alkalosis and electrolyte analysis hypokalemia. Other serum electrolytes, total creatine kinase, liver function tests, blood creatinine, hemoglobin, platelet and fibrinogen levels were normal. The findings of a brain CT scan were normal.

We treated the patient with intravenous electrolyte solution in order to correct the hypokalemia and maintain diuresis above $50-100 \mathrm{~mL} / \mathrm{h}$ to avoid the risk of myoglo- binuria, and diazepam to reduce anxiety and myoclonal seizures.

Our patient recovered completely within 10 hours after being admitted.

\section{Discussion}

Adverse effects associated with antidepressant drug therapy rarely cause significant morbidity or mortality. Serotonin syndrome results from therapeutic drug use, intentional self-poisoning, or inadvertent interactions between drugs. Nevertheless, it is most often reported in patients taking two or more medications that increase CNS serotonin levels by different mechanisms. The most common drug combinations associated with serotonin syndrome involve MAOIs, selective serotonin reuptake inhibitors (SSRIs), and tricyclic antidepressants ${ }^{4}$. Recent trends toward the use of medication combinations and augmentation therapies significantly enhance the risk of serotonin syndrome ${ }^{5,6}$. Because of the dramatic rise in the use of SSRIs, we encounter the serotonin syndrome more frequently than in the past ${ }^{1}$.

Clinical manifestations of the serotonin syndrome range from mild and barely perceptible to lethal ${ }^{7}$. Based on the patient history, clinical picture, illness course and laboratory findings in our case, we concluded that her condition could be related to serotonin syndrome caused by a combination of FLV, caffeine, propyphenazone and paracetamol. Hypotonia and muscle weakness, uncommon in SS, were in this case related to profound hypokalemia. Our patient met at least 6 of the Sternbach diagnostic crite$\mathrm{ria}^{2}$, and extensive medical and neurologic 
evaluations ruled out infectious, metabolic, and illicit substance-related etiologies.

More than 300 cases of overdosage with FLV, alone or in combination with other compounds, have been reported ${ }^{8-15}$. The most common symptoms of overdosage include gastrointestinal complaints, somnolence and dizziness. Cardiac events, liver function disturbances, convulsions and coma have also been reported. Among 300 patients revealed to have taken deliberate overdoses of FLV, there were 15 deaths, all but one of which occurred in patients who had confirmed to have taken multiple medications.

Adverse reactions to a single, therapeutic dose of FLV are very rare events in clinical practice $^{16}$. The hypothesized pathophysiologic mechanism of serotonine syndrome in this case is an overstimulation of serotonin (5-hydroxytryptamine or 5-HT) type 1A receptors (5-HT(1A)) in the brainstem and spinal cord. One important cause of adverse drug reactions is altered drug metabolism as a result of drug interactions mediated by the cytochrome P450 (CYP) drug oxidation system $^{17,18}$. Knowledge in this area has expanded rapidly in recent years and increasing numbers of clinically relevant interactions have been described. FLV is a potent inhibitor of CYP1A2, CYP3A3/4, and CYP2C9, and can also inhibit CYP2D6 and CYP2C19 (a minor metabolic pathway) ${ }^{19,20}$. FLV is unique as a potent inhibitor of CYP1A2. This enzyme acts on 5-10\% of drugs in current clinical use. In addition to affecting the metabolism of FLV, it also plays a major role in the metabolism of caffeine $^{21}$. Fluvoxamine significantly reduced the apparent oral clearance of caffeine and prolonged its elimination half-life ${ }^{22}$. Nevertheless, a recent study evaluating the effects of caffeine on the kinetics of plasma FLV in healthy male volunteers has proved that the neither the plasma concentration, nor the pharmacokinetic and pharmacodynamic parameters of FLV were affected by caffeine ${ }^{23}$. This study even suggested that caffeine slightly induces the metabolism of FLV, probably mediated by CYP1A2. Moreover, caffeine inhibits the CYP3A4 enzyme ${ }^{21,22}$. Paracetamol is metabolized mostly by CYP2E1, but can also inhibit the 1A2 enzyme $^{24}$. Propyphenazone uses CYP1A2, 2C9, 2C19 and 3A4 for its biotransformation $^{25}$, but there is no evidence of their serotonergic effects in available investigation data. We assume that the combination of fluvoxamine, caffeine and paracetamol produced higher than normal levels of that antidepressant in the blood. Respecting the fact that many headache patients take different kinds of analgesics, often together with antidepressants, without consequences, this particular patient probably belongs to the group of "slow metabolizers of SSRIs" (approximately $7 \%$ of the population $)^{26}$. In general, we can say that these chemicals concur for same metabolic pathways and produce higher levels of drugs in the organism than are normally expected.

Tension-type headache is considered the most common type of chronic recurring headache. About one-third of these patients have recognized symptoms of depression and respond best to the cautious use of one of several drugs that relieve anxiety or depression $^{27,28}$. Successful management of patients with depression requires the recognition of potential adverse effects that may have serious consequences, and consequently may necessitate the discontinuation of an otherwise effective therapy. Doctors who treat tension headache with antidepressants should be aware of the fact that this group of patients often concomitantly take different kinds of analgesics, some of which can interfere with the metabolism of serotoninergic 
$\operatorname{drugs}^{29}$. Consequently, physicians should take care to thoroughly inform their patients on possible adverse reactions, especially when antidepressants are taken together with other drugs. They are advised to provide their patients with a list of drugs that should be avoided.

No financial support declared. This article is in agreement with the local ethical standards of our institution.

\section{References}

1. Martin TG. Serotonin Syndrome. Ann Emerg Med 1996; 28: 520-526.

2. Sternbach H. The serotonin syndrome. Am J Psychiatry $1991 ; 148$ : 705-713.

3. Fennell J, Hussain M. Serotonin syndrome: case report and current concepts. Ir Med J 2005; 98: 143-144.

4. Sporer KA. The serotonin syndrome. Implicated drugs, pathophysiology and management. Drug Saf 1995; 13: 94-104.

5. Gillman PK. Serotonin syndrome: History and risk. Fundam Clin Pharmacol 1998; 12: 482-491.

6. Birmes P, Coppin D, Schmitt L, Lauque D. Serotonin syndrome: A brief review. CMAJ 2003; 168: 1439-1442.

7. Boyer EW, Shannon M. The serotonin syndrome. N Engl J Med 2005; 352: 1112-1120.

8. Karunatilake H, Buckley NA. Serotonin syndrome induced by fluvoxamine and oxycodone. Ann Pharmacother 2006; 40: 155-157.

9. Demers JC, Malone M. Serotonin syndrome induced by fluvoxamine and mirtazapine. Ann Pharmacother 2001; 35: $1217-1220$.

10. Gill M, LoVecchio F, Selden B. Serotonin syndrome in a child after a single dose of fluvoxamine. Ann Emerg Med 1999; 33: 457-459.

11. Ebert D, Albert R, May A, Merz A, Murata H, Stosiek I, et al. The serotonin syndrome and psychosis-like side effects of Fluvoxamine clinical use-an estimation of incidence. Eur Neurophychopharmacol 1997; 7: 71-74.
12. Bastani JB, Troester MM, Bastani AJ. Serotonin syndrome and fluvoxamine: A case study. Nebr Med J 1996; 81: 107-109.

13. Fluvoxamin. Brand name: Luvox. Drug Monograph. Internet Mental Health. Available at URL www.mentalhealth.com.

14. Deshpande K. Isolated fluvoxamine poisoning presenting with hypertonia and seizures. A case Report. Crit Care and Resusc 2002; 4: 177-180.

15. Mullins ME, Horowitz BZ. Serotonin Syndrome after a single dose of fluvoxamine. Ann Emerg Med 1999; 34: 806-807.

16. Baker GB, Fang J, Sinha S, Coutts RT. Metabolic drug interactions with selective serotonin reuptake inhibitor (SSRI) antidepressants. Neurosci Biobehav Rev 1998; 22: 325-333.

17. Preskorn SH. Reproducibility of the in vivo effect of the selective serotonin reuptake inhibitors on the in vivo function of cytochrome P450 2D6: An update (part II). J Psych Pract 2003; 9: 228-236.

18. Tanaka E, Hisawa L. Clinically significant pharmacokinetic drug interactions with psychoactive drugs: antidepressants and antipsychotics and the cytochrome P450 system. J Clin Pharm Ther 1999; 24: 7-16.

19. Xu ZH, Xie HG, Zhou HH. In vivo inhibition of CYP2C19 but not CYP2D6 by fluvoxamine. Br J Clin Pharmacol 1996; 42: 518-521.

20. Stahl SE. Essential Psychopharmacology, Neuroscientific Basis and Practical Applications, Second edition; Cambridge: Cambridge University Press; 2000.

21. Jeppesen U, Loft S, Poulsen HE, Brosen K. A fluvoxamine-caffeine interaction study. Pharmacogenetics 1996; 6: 213-222.

22. Culm-Merdek K, von Moltke LL, Harmatz JS, Greenblatt DJ. Fluvoxamine impairs single-dose caffeine clearance without altering caffeine pharmacodynamics. Br J Clin Pharmacol 2005; 60(5): 486-493.

23. Fukasawa T, Yasui-Furukori N, Suzuki A, Ishii G, Inoue $\mathrm{Y}$, Tateishi $\mathrm{T}$, et al. Effects of caffeine on the kinetics of fluvoxamine and its major metabolite in plasma after a single oral dose of the drug. Therapeutic Drug Monitoring 2006; 28(3): 308-311.

24. Manyike PT, Kharasch ED, Slattery JT. Assessment of the contribution of CYP2E1 and 3A4 to acetaminophen reactive metabolite formation in humans by treatment with disulfiram and rifampin. Clin Pharmacol Ther 2000; 67: 275-282. 
25. Pelkonen O, Maenpaa J, Taavitsainen P, Rautio A, Raunio H. Inhibition and induction of human cytochrome P450 (CYP) enzymes. Xenobiotica 1998; 28: 1203-1253.

26. Brown T, Skop B, Mareth T. Pathophysiology and management of the serotonin syndrome. Ann Pharmacother 1996; 30: 527-532.

27. Lance JW, Curran DA. Treatment of chronic tension headache. Lancet 1964; 1: 1236.

28. Victor M, Ropper AH. Tension headache. In Adams and Victor's Principles of Neurology, $7^{\text {th }}$ ed. 2001. New York: McGraw-Hill. p. 191-192.
29. Dalfen AK, Stewart DE. Who develops severe of fatal adverse drug reactions to selective serotonin reuptake inhibitors? Can J Psychiatry 2002; 47: 281-282.

Address for correspondence:

Sanja Kovacic

Department of Neurology

General Hospital Zabok

Bračak 6, 49210 Zabok,

Croatia

Tel: +385-49-221232

Fax: +385-49-221150

E-mail: sanja.drca@kr.htnet.hr 


\section{Linguistics \& Language Behavior Abstracts}

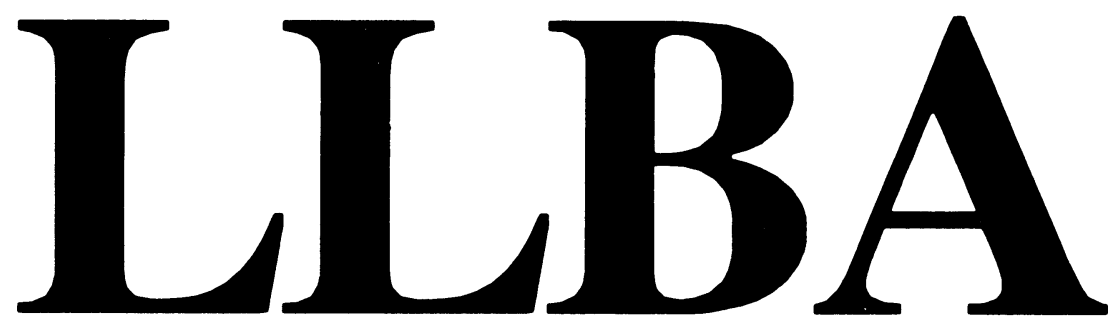

Now entering our 26 th year $(135,000$ abstracts to date) of senvice to linguists and language researchers worldwide. LLBA is available in print and also online from BRS and Dialog.

Linguistics \& Language Behavior Abstracts

$$
\text { P.O. Box } 22206
$$

San Diego, CA 92192-0206

Phone (619) 695-8803 FAX (619) 695-0416

Fast, economical document delivery available. 